\title{
ANÁLISE DE UM OBJETO DE APRENDIZAGEM SOB O VIÉS DO PAR DIALÉTICO EMPÍRICO E TEÓRICO
}

\author{
The Analysis of A Learning Object Under the View of the Empirical and Theoretical \\ Dialectical Pair
}

\author{
Josyleine Aparecida Bento da Silva* \\ Maria Lucia Panossian**
}

\begin{abstract}
Resumo: As transformações pelas quais a sociedade vem passando, devido acesso às Tecnologias de Informação e Comunicação, repercutem na forma como o ensino é organizado. Acredita-se que o uso dos computadores em ambientes escolares pode transformar o ensino e a aprendizagem. Para tanto, é importante que o professor esteja familiarizado com o seu potencial, considerando o computador como instrumento pedagógico na preparação de suas aulas. Com o intuito de auxiliar professores de Matemática no momento de construir ou escolher Objetos de Aprendizagem (OA) para serem utilizados em suas aulas como instrumentos pedagógicos, o presente artigo tem por objetivo apresentar uma análise do OA 'Jogo de Bilhar', aplicado ao ensino da trigonometria no triângulo retângulo, a luz do par dialético empírico e teórico. Entende-se que este pode ser um indicador de análise de Objetos de Aprendizagem auxiliando o professor na escolha de situações de ensino e/ou Objetos de Aprendizagem para desenvolver em suas aulas. Este texto é parte de uma dissertação que trata sobre OA aplicados ao ensino da trigonometria sob a luz dos pares dialéticos. Para este artigo foi realizada a análise somente de um objeto, este selecionado por pertencer a um site de propriedade do Ministério da Educação (MEC). Não obstante, a análise de outros objetos pode ser encontrada no texto completo da dissertação publicada pela Universidade Tecnológica Federal do Paraná.
\end{abstract}

Palavras-chave: Teoria Materialista Histórica-Dialética. Objeto de Aprendizagem. Ensino da Trigonometria.

\begin{abstract}
The transformations which society has been going through, due to the access to Technologies of Information and Communication, reverberate in the way teaching is organized. It is believed that the use of computers in school environments can transform teaching and learning. Therefore, it's important that the teacher gets familiar with its potential, considering it as a pedagogical instrument in the preparation of their classes. In order to help math teachers creating or choosing Learning Objects (LO) to be used in their classes as pedagogical instruments, this article aims to show an analysis of the LO - Billiard Game applied to the teaching of trigonometry at the rectangle triangle, based on the pair empirical and theoretical dialectics. It's understood that this can be an indicator of an analysis of Learning Objects, helping the teacher to choose teaching situations and/or Learning Objects to develop in their

\footnotetext{
*Mestre pelo Programa de Formação Científica, Tecnológica e Educacional da UTFPR, Professora de Matemática da rede pública da Prefeitura Municipal de Curitiba. orcid.org/0000-0001-5992-7562. EE-mail: josyleine.silva@gmail.com

** Doutora em Educação pela Universidade de São Paulo. Professora do Departamento Acadêmico de Matemática da Universidade Tecnológica Federal do Paraná. orcid.org/0000-0001-5847-4485. E-mail: mlpanossian@utfpr.edu.br
} 
classes. For this article the analysis of just one object was made, which was selected because it belongs to a site that is under the Ministério da Educação (MEC) property. The analysis of other objects can be found in the complete study of the dissertation published by Universidade Tecnológica Federal do Paraná.

Keywords: Historical-Dialectical Materialist Theory. Learning Object. Teaching trigonometry.

\section{Introdução}

A utilização das Tecnologias de Informação e Comunicação (TIC) em sala de aula pode tornar o ambiente de ensino mais dinâmico e capacitar os estudantes para a apropriação e produção do conhecimento (NAVARRO, 2015). A presença do computador e de outros recursos tecnológicos nas classes, associados com propostas de ensino contextualizadas, podem oferecer resultados que potencializem o aprendizado dos estudantes, desde que sejam selecionados de forma adequada.

Diante desse quadro, acredita-se no potencial de investigação e de estudo sobre o uso das TIC no processo de aprendizado dos estudantes no ambiente escolar. Do mesmo modo, acredita-se na necessidade do aprofundamento sobre o impacto dessas tecnologias na prática pedagógica em Educação Matemática.

Atualmente, observa-se que os estudantes apresentam dificuldades ao estudarem a trigonometria no triângulo retângulo. Segundo Martin, Ruiz e Rico (2016), a trigonometria não é um conteúdo escolar de fácil aprendizado devido a várias razões, entre elas, a sua complexidade, conexão com numerosos fenômenos e principalmente a falta de contextualização por parte dos professores em sua exposição. A forma como o conteúdo da trigonometria é apresentado aos estudantes pode gerar conflitos de interpretação e assimilação insuficiente dos seus conceitos básicos, o que resultará em empecilhos ao processo de ensino e aprendizagem.

Frente a essas dificuldades relacionadas à introdução do conteúdo da trigonometria, este artigo pretende propor uma análise do Objeto de Aprendizagem (OA) - Jogo de Bilhar, de acordo com o par dialético empírico-teórico, análise esta fundamentada no materialismo histórico-dialético. Com a análise do OA a partir desse par dialético, pretende-se auxiliar professores no momento que estes necessitarem escolher ou desenvolver OA aplicados ao ensino da trigonometria no triângulo retângulo.

\section{Objetos de Aprendizagem: a presença da TIC no ambiente escolar}

A introdução dos primeiros computadores em ambiente escolar começou a ocorrer no final do século passado, época em que a apresentação do conhecimento para os estudantes era realizada apenas pela aula tradicional ministrada pelo professor (MALTEMPI, 2005). Ao longo das últimas décadas, educadores matemáticos têm discutido as políticas públicas de participação das TIC nas salas de aula (BORBA; LACERDA, 2015). Destarte, em alinhamento a premência da sociedade, os intentos de estreitar o uso da informática na educação corroboraram para transformar o computador em um instrumento de ensino, disseminador de conhecimento (MALTEMPI, 2005).

A utilização de recursos das TIC, podem contribuir para motivação e curiosidade por parte dos estudantes no desenvolver do processo de ensino e da aprendizagem. 
As tecnologias de informação e comunicação (TIC) ao serem inseridas na sala de aula transformam tanto o cenário escolar quanto a estrutura do processo de construção do conhecimento. A maneira como o professor aborda os conteúdos e as suas compreensões pelos alunos sofrem modificações com a utilização das novas tecnologias (JANEGITZ, 2016, p. 34).

Dentre os recursos que as TIC podem disponibilizar para o ensino e aprendizagem, encontra-se os Objetos de Aprendizagem (OA). Os OA são um aliado em sala de aula para o professor organizar o ensino de um determinado conteúdo. Mas, para que o objetivo esperado na aprendizagem seja alcançado pelo professor, ele deve ter a consciência de escolher o OA apropriado para a sua atividade didática, entende-se que os OA por permitirem a adaptação dos conteúdos escolares às reais necessidades dos alunos, podem tornar as aulas mais atrativas (AGUIAR; FLORES, 2014).

Segundo o Grupo de Pesquisas sobre Tecnologias na Educação Matemática (GPTEM) da Universidade Tecnológica Federal do Paraná (UTFPR) e da Universidade Federal do Paraná (UFPR), OA é definido como:

[...] qualquer recurso virtual multimídia, que pode ser usado e reutilizado com o intuito de dar suporte a aprendizagem de um conteúdo específico, por meio de atividade interativa, apresentada na forma de animação ou simulação (BALBINO; KALINKE, 2016, p. 25).

Para Tikhomirov (1981), o desenvolvimento e o uso das TIC têm instigado o conhecimento psicológico a ponto de provocar mudanças na atividade intelectual humana, a qual pode se transformar em uma forma mais complexa, desde que o recurso da TIC esteja tecnicamente adequado e adaptado a esta atividade humana e o ser humano seja receptivo em aceitar e harmonizar seu trabalho com o uso do computador. Tecnologias estas que, segundo Kopnin (1978), se utilizadas pelo homem como instrumento de trabalho, o ajudam a conhecer e a transformar o mundo.

\section{Fundamentos teóricos: o par dialético empírico-teórico e implicações da teoria histórico- cultural}

A dialética, inicialmente por volta de 300 a. C, era entendida pelos gregos antigos, principalmente por Platão e Aristóteles, como a arte da discussão à base de perguntas e respostas, além de ressaltar o caráter contraditório do ser. Georg Wilhelm Friedrich Hegel (1770-1831),apresentou a dialética como a natureza do mundo em constante movimento, ou seja, em constante transformação, mudança e desenvolvimento. Já na visão materialista de Karl Marx (1818-1983), a contribuição da dialética iria além da contradição.

Kopnin (1978), apresenta a dialética como uma doutrina que estuda a unidade dos contrários e entende que as leis do materialismo histórico-dialético para Kopnin (1978), só se revelam em seus pares dialéticos, que, por sua vez, estabelecem a lógica do pensamento científico teórico, ou seja, criação do movimento de um conceito a outro com mais propriedade em relação ao objeto em estudo. Nesse processo de desenvolvimento haverá categorias com propósitos contrários, mas que não podem existir um sem a presença do outro, como afirma Trivinos (2011, p. 69), ao discorrer que os "contrários interpenetram-se, porque em sua essência 
tem alguma semelhança, alguma identidade, que se alcança quando se soluciona a contradição, quando se realiza a passagem dos contrários de um para o outro.”.

A dialética proporciona um conjunto de categorias ou pares dialéticos que atuam no movimento do pensamento e são formas inter-relacionadas que se constituem como unidades de contrários. Como exemplos, temos os pares dialéticos empírico/teórico, lógico/histórico, concreto/abstrato, forma/conteúdo, etc. (MARTINS, SOUZA, e MORETTI, 2016; KOPNIN, 1978). Todos os pares dialéticos estão relacionados entre si. E "todas as categorias do materialismo dialético, começando pela matéria, implicam a solução do problema da relação do pensamento com o ser." (KOPNIN, 1978, p. 60).

Se podemos entender que os pares dialéticos explicitam o movimento do pensamento e sua relação com o ser e com o conhecimento, podemos entender também que no processo de ensino, tais pares dialéticos podem nos ajudar a compreender tanto o processo de constituição histórico de um determinado conceito quanto o seu processo de organização para o ensino.

Por isso, neste texto, tem-se a intenção de investigar possibilidades de análise de um objeto de aprendizagem específico a partir de um par dialético, no caso, o par empírico e teórico.

Na sequência, será apresentada a compreensão sobre esse par.

\section{Par Dialético: empírico e teórico}

O pensamento é uma atividade intelectual teórica do homem à sua consciência, logo, ele unifica o sujeito e o objeto. Dessa forma, o objeto deve estar em sintonia com a atividade do sujeito. O homem, a partir do pensamento produz conceitos partindo de pares de contrários que se fazem como unidade de opostos (KOPNIN, 1978).

Para entender e explicar este movimento do conhecimento que prepara a atividade do pensamento, é necessária a existência de uma lógica, a lógica dialética materialista, a qual procura sempre conduzir este movimento no sentido da obtenção de resultados que levem a formação de novos conceitos científicos. Na lógica dialética, esta divisão do pensamento aparece como pensamento empírico e teórico (KOPNIN, 1978).

O pensamento empírico é decorrência de interpretações sensoriais, ou seja, uma generalização formada por um princípio de concordância abstrata e formal, que assentarão a base para a construção do conteúdo concreto. As "relações empíricas podem ser expressadas verbalmente como os resultados das observações sensoriais." (DAVYDOV, 1990, p. 119, tradução nossa). Logo, o pensamento empírico, por sua vez, será o ponto de partida para a construção do conhecimento.

\footnotetext{
No pensamento empírico o objeto é representado no aspecto das suas relações e manifestações exteriores acessíveis à contemplação viva. A forma lógica do empírico é constituída pelo juízo tomado isoladamente, que constata o fato ou por certo sistema de fatos que descreve um fenômeno. A aplicação prática do conhecimento empírico é restrita, sendo, no sentido científico, um ponto de partida qualquer para a construção da teoria. (KOPNIN, 1978, p. 152).
}

Quanto às relações no campo externo, Davydov (1990), expõe que no pensamento empírico pode-se constatar a repetição externa, analogias e dissociação de partes. Já as relações internas e essenciais não se deixam ser reveladas diretamente pelos sentidos, mas podem ser 
identificadas através das mediações estabelecidas entre o presente vivenciado, o qual deve ser confrontado com o passado e com o eventual futuro.

Segundo Davydov (1990), o pensamento teórico é composto pelo ser mediado e é resultado da atividade prática por objetos e pela reprodução destes objetos na atividade do trabalho, pelas suas leis e medidas, como uma experiência de caráter objeto-sensorial. Por conseguinte, essa experiência "adquire cada vez mais um caráter cognitivo, permitindo às pessoas, com o tempo, passar a uma experimentação mental, a mentalmente atribuir uma certa interação, uma forma definida do movimento, a objetos." (DAVYDOV, 1990, p. 116, tradução nossa). Sendo essa experimentação mental o eixo fundamental do pensamento teórico, de vez se efetiva pelos conceitos científicos.

\begin{abstract}
O pensamento teórico reflete o objeto no aspecto das relações internas e leis do movimento deste, cognoscíveis por meio da elaboração racional dos dados do conhecimento empírico. Sua forma lógica é constituída pelo sistema de abstrações que explica o objeto. A aplicação prática do conhecimento teórico é quase ilimitada, enquanto no sentido científico a construção da teoria se manifesta como um resultado final, como conclusão do processo de conhecimento. (KOPNIN, 1978, p. 152).
\end{abstract}

De acordo com Panossian (2008), tanto o conhecimento empírico quanto o conhecimento teórico têm como referência comum a percepção dos objetos. No entanto, o conhecimento teórico vai além da externalidade, que expõe apenas as propriedades individuais do objeto, e procura construir o conceito através de relações entre suas propriedades nos mais diversificados meios de atividade intelectual.

Dessa forma, o desenvolvimento e o uso das TIC têm influenciado o conhecimento psicológico a ponto de provocar mudanças na atividade intelectual humana. Essa atividade humana pode se transformar em uma forma mais complexa, através da mediação do computador, desde que este computador esteja tecnicamente adequado e adaptado à atividade humana e o ser humano receptivo em aceitar e harmonizar seu trabalho com o uso do computador (TIKHOMIROV, 1981).

\title{
5 Metodologia
}

A metodologia da pesquisa presente neste artigo desenvolveu-se por meio da abordagem da teoria histórico-dialética, que procura captar a essência do fenômeno, e não apenas a sua aparência, advogando por uma metodologia com evidência aos aspectos qualitativos ao invés dos quantitativos (DAMAZIO, 2006). Buscando também "as causas da existência dele, procurando explicar sua origem, suas relações, suas mudanças e se esforça por intuir as consequências que terão para a vida humana." (TRIVINOS, 2011, p. 129).

O processo investigativo deu-se em duas etapas: no primeiro momento, houve a seleção do OA em repositórios que se encontram na rede de computadores mundial - a internet. No segundo momento, foi realizada a análise do OA selecionado.

Para investigar os sites dos repositórios, foram utilizados alguns critérios no momento da seleção dos OA, tais como:

a) foram selecionados OA de sites vinculados ao Ministério da Educação (MEC), a instituições de ensino, ou a sites relacionados a educação;

b) os repositórios investigados, deveriam apresentar o idioma português; 
c) de acordo com a definição do GPTEM, foram selecionados os OA, que apresentem recurso virtual multimídia e interativo, apresentado na forma de animação ou simulação;

d) para encontrar os OA no repositório do site selecionado, foi utilizado a palavra-chave: trigonometria;

e) para restringir o estudo dessa pesquisa, dentro do extenso conteúdo da trigonometria, foram selecionados $\mathrm{OA}$ que estivessem aplicados ao ensino da trigonometria no triângulo retângulo.

Para fazer a análise dos OA aplicados ao ensino da trigonometria no triângulo retângulo, foram consultados dez sites com repositórios de OA. Os sites Noas e Rived, apresentaram concomitantemente um OA, já o site Klan Academy apresentou dois OA em seu repositório. Os sites Banco Internacional de Objetos Educacionais, Domínio Público, LEC, Proativa, Portal do Professor e Unijuí, não revelaram OA que tratassem do ensino de trigonometria no triângulo retângulo em seus repositórios. O site Scratch, por sua vez, apresentou quatro OA.

Desta seleção, optou-se por analisar o OA -Jogo de Bilhar, do repositório Rived ${ }^{1}$, pertencente ao portal da Secretaria de Educação a Distância, por ser um site de propriedade do Ministério da Educação. Na sequência, este OA foi analisado à luz da teoria materialista histórico-dialética e de acordo com os pressupostos do par dialético empírico e teórico.

\section{Analisando o Objeto de Aprendizagem - Jogo De Bilhar}

O OA Jogo de Bilhar, é um jogo educacional interativo e dinâmico de acordo com a definição do GPTEM. Encontra-se disponível no repositório do RIVED, site de idioma português, o qual trata da trigonometria no triângulo retângulo. Apresenta seis links de acesso entre eles motivação, introdução, noções básicas, as funções trigonométricas, aplicações e autores (Figura 1).

Figura 1 - OA Jogo de Bilhar - conceitos fundamentais

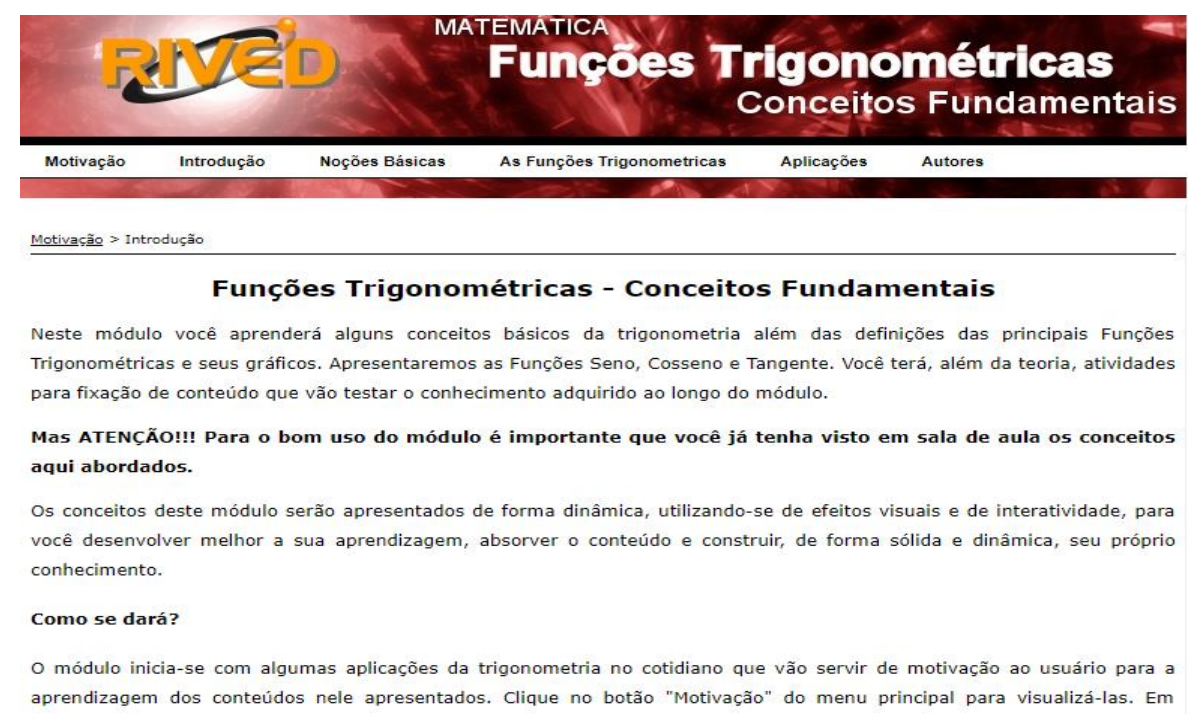

Fonte: http://rived.mec.gov.br/atividades/matematica/mundo_trigonometria/

\footnotetext{
${ }^{1}$ Disponível em: http://rived.mec.gov.br. Acesso em: 18 ago 2019.
} 
No link 'motivação' o OA traz situações em que o uso de trigonometria pode ser aplicado no cotidiano de uma pessoa, e, como exemplo são citados os jogos de futebol, rapel, canoagem e o próprio jogo de bilhar. O link 'introdução' discorre sobre como dar-se-á o OA Jogo de bilhar e como o usuário poderá usá-lo. Já ao clicar no link 'autores' é apresentado as pessoas pertencentes a equipe idealizadora do OA.

O link 'noções básicas' está elencando sob a forma de três sub links, que trarão uma breve revisão sobre determinados conteúdos e conceitos da trigonometria. Na Introdução há uma explicação para diversas aplicações práticas da trigonometria. Na sequência, traz um texto sobre um pouco da história da trigonometria. No sub link arcos e ângulo, é apresentada uma revisão dos conceitos de arcos, ângulos, grau, radianos. Finalmente, no círculo trigonométrico, é evidenciada uma revisão dos conceitos da circunferência trigonométrica, do círculo trigonométrico e quadrantes.

Por fim, o link 'funções trigonométricas' explica separadamente em três sub links as funções seno, cosseno e tangente, que, por sua vez, trarão individualmente mais quatro sub links compostos de: definição, função trigonométrica, gráficos e atividade. Esse último sub link, por sinal, aparece somente para as funções seno e cosseno. $\mathrm{O}$ sub link atividade é interativo e permite ao estudante traçar o movimento de um ponto no círculo trigonométrico e, concomitantemente, simular o gráfico da função seno ou cosseno (Figura 2).

Figura 2 - OA Jogo de Bilhar - funções trigonométricas

\section{GRÁFICO DA FUNÇÃO y $=$ sen $x$}

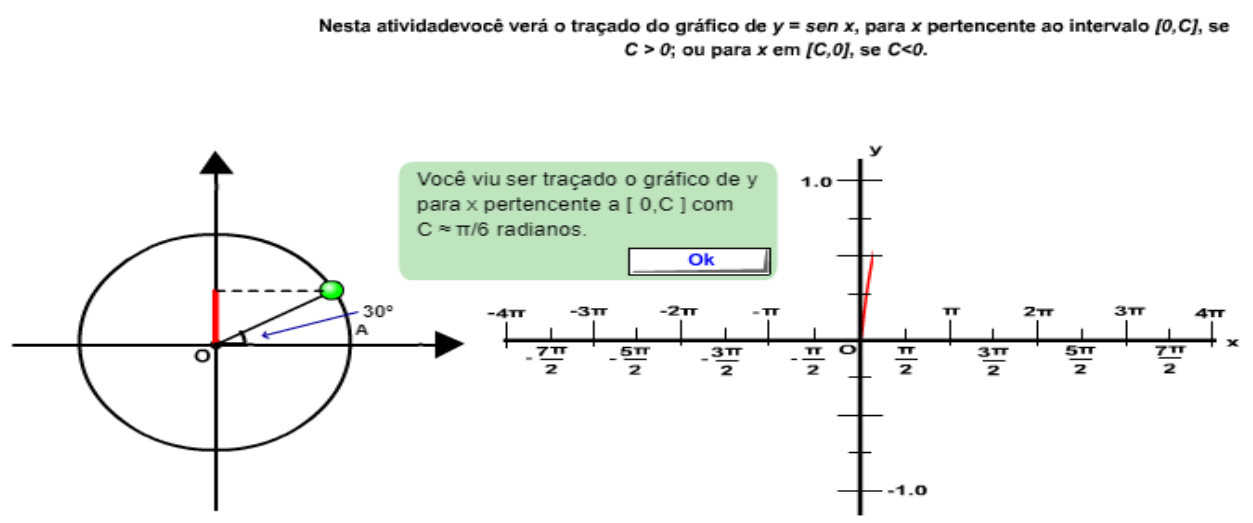

Fonte:http://rived.mec.gov.br/atividades/matematica/mundo_trigonometria/

O OA do sub link das funções trigonométricas apresenta a organização do conteúdo da trigonometria na forma de uma revisão textual, material este análogo aos dos livros didáticos. Esse OA apresenta uma certa interatividade ao estudante, no momento em que ele precisa inserir o valor do ângulo no campo solicitado, o qual, como resposta apresenta a construção do gráfico das razões trigonométricas.

Destarte, a aplicação desse OA, que pertence ao sub link das funções trigonométricas, solicita apenas que o estudante insira um valor no campo destinado ao ângulo, justificando o pensamento empírico e impossibilitando o estudante de articular os conceitos trigonométricos para seu entendimento, não favorecendo a construção do pensamento teórico e possibilitando ao estudante apenas um trabalho mecânico, como descreve Tikhomirov (1981). 
Psicologicamente, conhecimento é a reflexão de algumas relações essenciais entre os objetos à volta. É um sistema de generalizações. Quando uma pessoa aprende "mecanicamente", ela determina apenas a conexão entre a pergunta e a resposta (é outra questão que, na sua forma pura, este fenômeno é raramente visto). Quando alguma informação é significativamente adquirida, é sempre incluída em algum sistema da experiência passada da pessoa. (TIKHOMIROV, 1981, p. 7).

No link 'aplicações', encontramos o OA propriamente dito, o jogo de Bilhar (Figura 3). Ao iniciá-lo, observamos que a aplicação do OA apresenta uma situação problema que exige por parte do estudante a resposta de duas perguntas, uma chamada mesma de "Pergunta" e outra "Opcional". A opção "Pergunta" tem caráter obrigatório, ou seja, o estudante precisa acessá-la para obter a resolução que permitirá a ele que dê a sua tacada para a próxima fase do OA (Figura 4).

Figura 3 - OA Jogo de Bilhar - RIVED

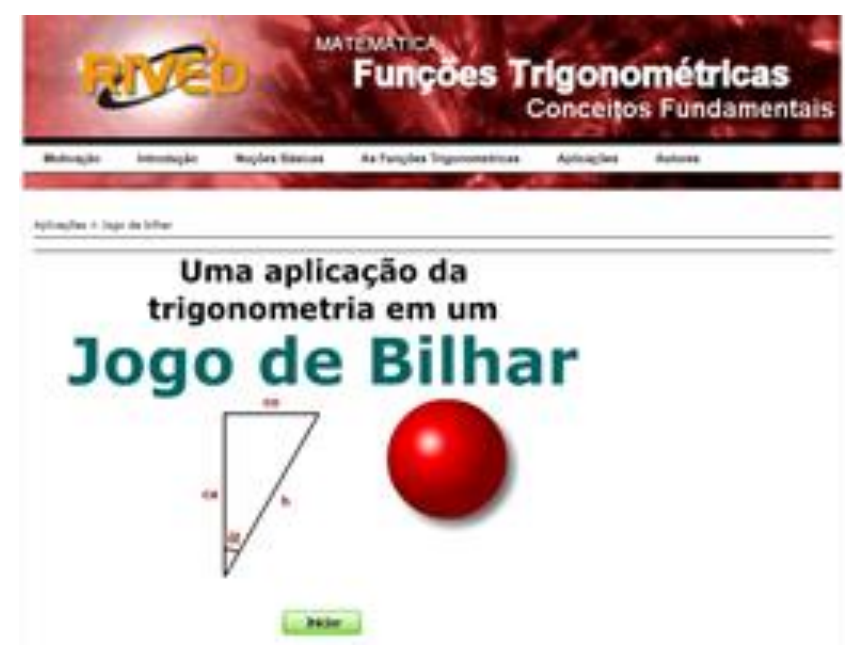

Fonte: http://rived.mec.gov.br/atividades/matematica/mundo_trigonometria/

Figura 4 - OA Jogo de Bilhar - pergunta

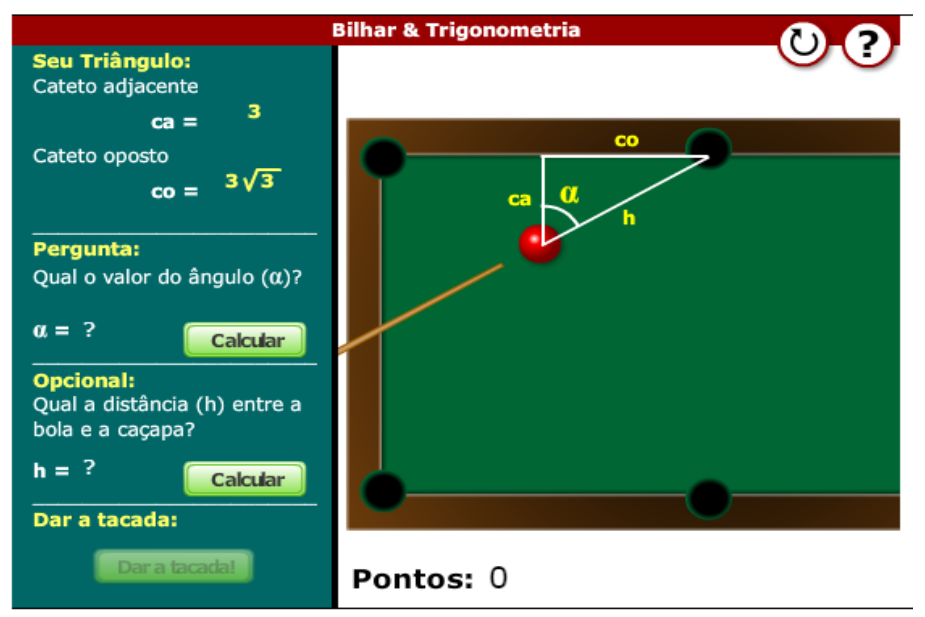

Fonte: http://rived.mec.gov.br/atividades/matematica/mundo_trigonometria/ 
$\mathrm{Na}$ opção "Pergunta", é indagado ao estudante qual o valor do ângulo $\alpha$. O estudante, ao clicar em calcular, perceberá que o cálculo do valor do ângulo $\alpha$ do triângulo formado na mesa de bilhar já está pronto, ou seja, o estudante não precisará realizá-lo. Observa-se que a pergunta de opção obrigatória apresenta apenas uma verificação do cálculo da tangente para determinar o ângulo (Figura 5).

A partir da leitura de Kopnin (1978), considerou-se que a resolução dessa pergunta não desencadeia um movimento do pensamento empírico ou teórico, pois somente mostra o cálculo e não exige nenhuma ação física ou mental do estudante, a não ser olhar o que já está feito. Pensamento esse que vai de encontro com a posição de Davydov (1990), ao escrever que operar uma atividade apenas por representações e não através dos conceitos não levará o estudante a construir o pensamento teórico.

Figura 5 - OA Jogo de Bilhar - resolução da pergunta

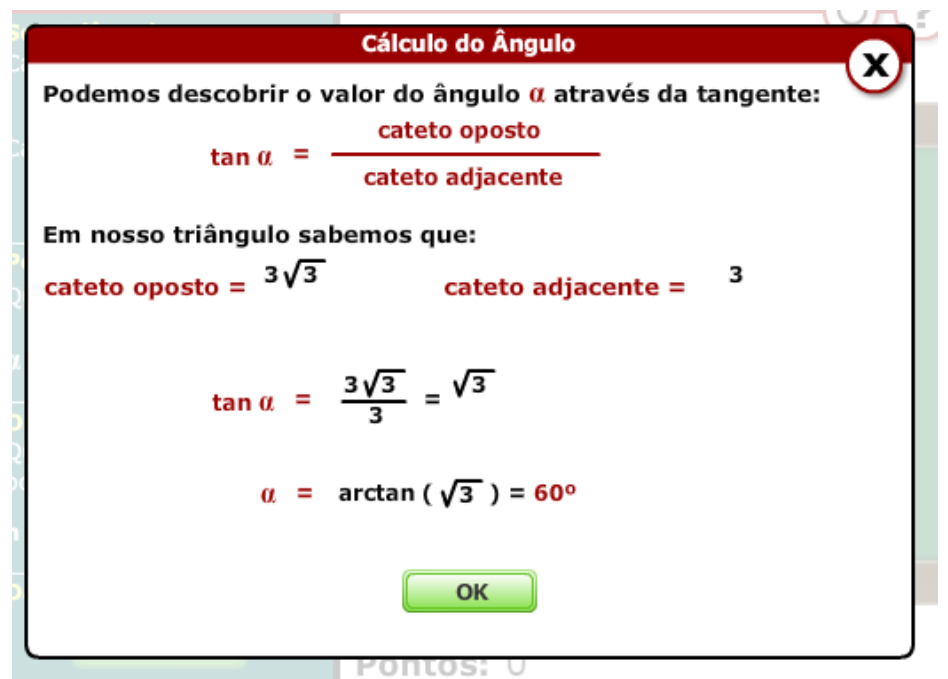

Fonte: http://rived.mec.gov.br/atividades/matematica/mundo_trigonometria/

Na pergunta "Opcional", é solicitado ao estudante que encontre o valor da distância entre a bola e a caçapa. Para este cálculo, é fornecido ao estudante os valores dos catetos opostos e adjacentes do triângulo formado na mesa de bilhar, e inclusive, a fórmula do teorema de Pitágoras. Logo, o estudante somente terá o trabalho de inserir os valores fornecidos na fórmula e encontrar o valor para a hipotenusa (Figura 6). Em seguida, poderá dar a tacada para a próxima fase da aplicação do OA (Figura 7). Por consequência, nessa atividade o estudante "é liberto não do trabalho mecânico, mas do trabalho criativo." (TIKHOMIROV, 1981, p. 10).

Novamente, encontramos apenas a presença do pensamento empírico, porque o estudante não precisará externalizar seu conhecimento, ou seja, como afirma Panossian (2008), não lhe será exigido que utilize de relações entre as propriedades da trigonometria para articular seus conceitos científicos, proporcionando o pensamento teórico. 
Figura 6 - OA Jogo de Bilhar - resolução da pergunta opcional

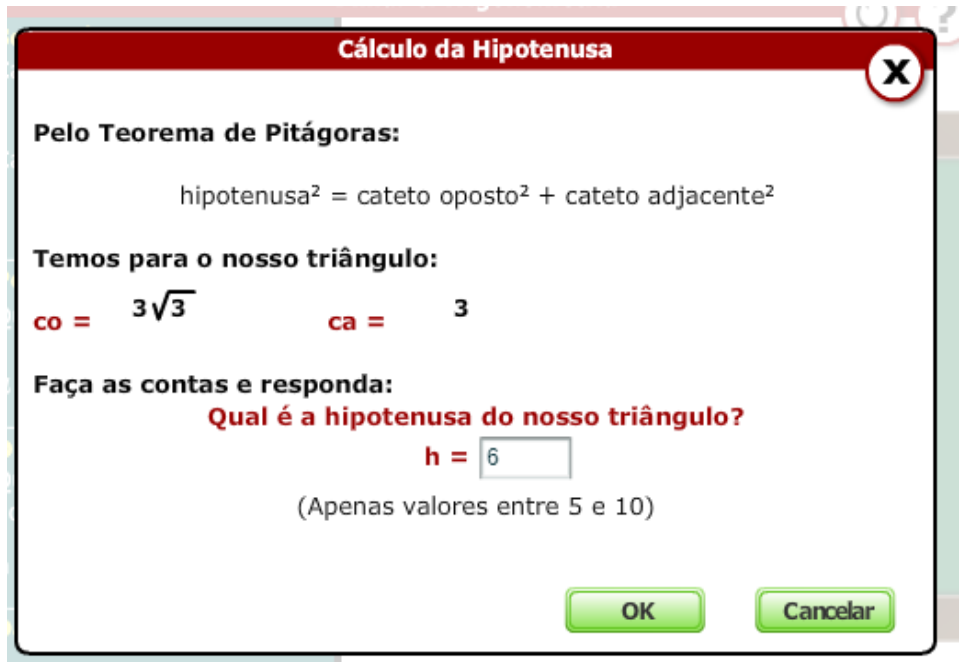

Fonte: http://rived.mec.gov.br/atividades/matematica/mundo_trigonometria/

Figura 7 - OA Jogo de Bilhar - Parabéns

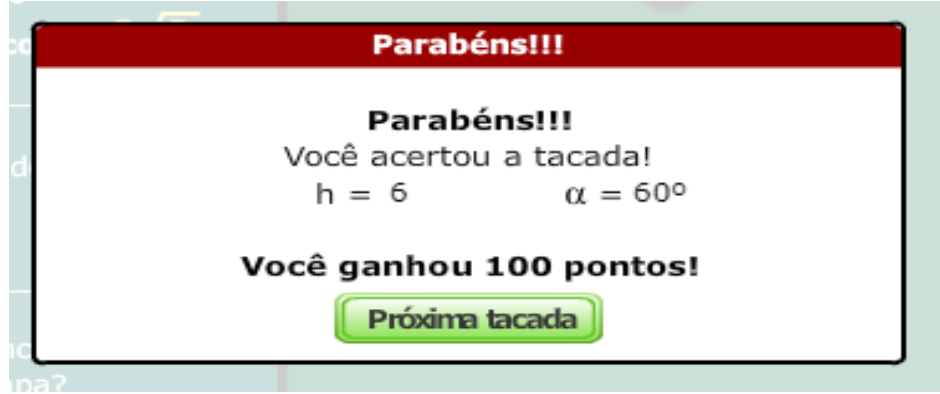

Fonte: http://rived.mec.gov.br/atividades/matematica/mundo_trigonometria/

Caso o aluno erre a resposta, ele tem as opções de voltar e resolver novamente a questão ou dar a tacada para a próxima fase sem a necessidade de respondê-la, por ser uma pergunta opcional. Esse tipo de pergunta, como já descrito anteriormente, pode não motivar o estudante a realizar os cálculos necessários para obtenção da sua resposta. Logo, o aprendizado com a realização dos cálculos pode não ser alcançado por parte dos estudantes, que não se sentirão instigados a realizar esta etapa da aplicação do OA.

De acordo com Davydov (1990), o estudante terá somente uma experiência sensorial de leitura, meramente uma manifestação do pensamento empírico, ou seja, a forma como o conteúdo é apresentado, apesar de ser interativo, não sugere simulações e nem inovações, portanto não estimula o processo lógico de recorrer a abstrações para construir o conceito.

Dando sequência ao jogo, as novas etapas da aplicação do OA irão apresentar o mesmo layout, com as mesmas duas perguntas da primeira etapa. Novamente o estudante será convidado a realizar o mesmo processo, com mudanças apenas nos valores numéricos dos catetos e do ângulo $\alpha$ do triângulo apresentado na mesa de bilhar. Processo este empírico, no qual, segundo Davydov (1990), não ocorre a presença do movimento de articulação entre os conceitos. 
Ao realizar a análise do OA quanto a presença de elementos do pensamento teórico, observou-se que as atividades do jogo apresentado pelo objeto, não exigiam dos estudantes nexos entre os conceitos trigonométricos. Logo, revelou-se primordialmente elementos do pensamento empírico, à medida que, o estudante não precisou externalizar seu conhecimento, ou seja, como afirma Panossian (2008), não lhe será exigido que utilize de relações entre as propriedades da trigonometria para articular seus conceitos científicos, proporcionando o pensamento teórico.

Para apresentar em sua forma o movimento, a necessidade de abstrações, ou articulações entre os conceitos do conteúdo da trigonometria, o OA precisaria desencadear a necessidade do estudante de perceber a inclinação dos ângulos e como a mudança nesta inclinação gera mudanças nas razões estabelecidas entre os lados do triângulo (razões trigonométricas). Dessa forma, o OA poderá proporcionar ao estudante a formação do pensamento teórico.

\section{Considerações finais}

Os autores da TIC indicam que a inserção do uso de OA no planejamento das aulas pode transformar o ensino e a aprendizagem do estudante. Concorda-se que o seu uso pode exercer transformação, contudo isso dependerá da qualidade e da forma como é organizado o ensino para este OA. Ao estudar os autores da teoria materialista histórico-dialética, constatou-se que o conhecimento pode ser estimulado e apropriado pelo estudante quando ele é trabalhado no coletivo, dentro de um contexto histórico e cultural que obedece às leis da dialética e em que se reconhece a lei da contradição dos pares dialéticos do movimento da construção do pensamento empírico-teórico.

Constatou-se ao analisar o OA - Jogo de Bilhar, que sua manipulação não dispõe o estudante a gerar generalizações e abstrações, pelo contrário, apenas o conduz a agir mecanicamente, ao apenas realizar um cálculo por uma fórmula induzida pelo OA, comprometendo como afirma Tikhomirov (1981), a atividade criativa do estudante.

Ao observar e analisar o OA, averiguou-se que sua aplicação instiga no estudante a formação do pensamento empírico, ou seja, não leva o aluno a formas do pensamento teórico e articulações entre os conceitos. Sabemos o quanto é relevante a presença destas formas de pensamento no momento em que o estudante irá articular os conceitos para erigir o conhecimento científico.

Dessa forma, nas palavras de Kopnin (1978), ao mesmo tempo que os dois pensamentos evidenciam momentos relativamente autônomos, também apresentam o objeto com consonância, pois, no desenvolver dos estudos, o que é inicialmente pensamento empírico irá evoluir para pensamento teórico, e ao ser dado sequência nestes estudos, o que era pensamento teórico, na nova etapa de estudos, passará a ser pensamento empírico.

Não se desconsidera a importância da forma de pensamento empírico no processo de construção do conhecimento científico, entretanto ele é insuficiente para a formação do conceito. Não obstante, o uso desse OA não irá contribuir para a transformação do ensino e da aprendizagem no estudante, de uma forma que esse construa conceitos científicos e teóricos.

Espera-se que esta análise do OA - Jogo de Bilhar, sob a luz da análise do par dialético pensamento empírico-teórico, possa oferecer subsídios pedagógicos aos professores para que estes possam ter um indicador no momento de selecionar, analisar ou criar um OA aplicado ao ensino da trigonometria no triângulo retângulo. Destaca-se ainda que mais informações referentes a esta e outras análises de OA, bem como a apresentação de um OA sobre o ensino 
da trigonometria no triângulo retângulo, a partir do movimento histórico e lógico podem ser encontrados em Silva (2018).

\section{Agradecimentos}

Esta pesquisa está vinculada ao projeto universal "Situações de ensino de conteúdo matemático: estabelecendo parâmetros e critérios de análise" financiada pelo Conselho Nacional de Desenvolvimento Científico e Tecnológico (CNPq), com o número do processo 408701/2016-1.

\section{Referências}

AGUIAR, E. V. B.; FLORES, M. L. P. Objetos de Aprendizagem: Conceitos básicos. In: TAROUCO, L. M. R. et al. Objetos de Aprendizagem: teoria e prática. Porto Alegre: Editora Evangraf Ltda. 2014. p. 12-28.

BALBINO, R. O.; KALINKE, M. A. Lousa digital e outras tecnologias na Educação Matemática. In: KALINKE, M. A, MOCROSKY, L. F. (org.). Lousa Digital e outras tecnologias na Educação Matemática. Curitiba: CRV, 2016, p. 13-32.

BORBA, M. C; LACERDA, H. D. G. Políticas públicas e Tecnologias Digitais: um celular por aluno. Educação Matemática e pesquisa, São Paulo, v.17, n.3, pp.490-507, 2015.

DAMAZIO, A. Elaboração de conceitos matemáticos: Abordagem histórico-cultural. In: REUNIÃO ANUAL - ASSOCIAÇÃO NACIONAL DE PÓS-GRADUAÇÃO E PESQUISA EM EDUCAÇÃO, 29, 2006, Caxambu. Anais [...]. Caxambu, 2006. [p. 1-19.].

DAVIDOV, V. V. Types of generalization in instruction: logical and psychological problems in the structuring of school curricula. Translated by Joan Teller. Reston Virginia: Published by the National Council of Teachers of Mathematics, 1990.

JANEGITZ, L. E. Lousa digital e outras tecnologias na Educação Matemática. In: KALINKE, M. A, MOCROSKY, L. F. (org.). Lousa digital e outras tecnologias na Educação Matemática. Curitiba: CRV, 2016, p. 33-56.

KOPNIN, P. V. A dialética como lógica e teoria do conhecimento. Rio de Janeiro: Editora Civilização Brasileira S.A, 1978.

MALTEMPI, M. V. Novas tecnologias e construção de conhecimento: reflexões e perspectivas. In: V Congresso ibero-americano de Educação Matemática (CIBEM). Porto, Portugal, 17 a 22 de julho. 2005. 
MARTINS, E.; SOUZA, F. D. E MORETTI, V. D. Método Histórico-Dialético, Teoria Histórico-Cultural e Educação: Algumas apropriações em pesquisas sobre formação de professores que ensinam matemática. In: MORETTI, V. D.; LIMA, W. (org). Educação Matemática e a teoria histórico-cultural: um olhar sobre as pesquisas. Campinas: Mercado das letras 2017. p. 25-60.

NAVARRO, E. R. Lousa Digital: investigando o uso na rede estadual de ensino com o apoio de um curso de formação. 144 fls. Dissertação (Mestrado em Educação Matemática) -

Universidade Federal do Paraná, Curitiba, 2015.

PANOSSIAN, M. L. Manifestações do pensamento e da linguagem algébrica de estudantes: indicadores para a organização do ensino.2008. 179 f. (Mestrado em Educação) Faculdade de Educação da Universidade de São Paulo, São Paulo, 2008.

SILVA, J. A. B. Objetos de Aprendizagem aplicados ao ensino da trigonometria: revelando elementos a partir do movimento histórico e lógico.2018. Dissertação (Mestrado em Formação Científica, Educacional e Tecnológica). Universidade Tecnológica Federal do Paraná, Curitiba, 2018.

TIKHOMIROV, O. K. The Psychological Consequences of Computarization. In Wertsch, J. V. (Ed.). The Concept of Activity in Soviet Psychology. New York: M. E. Sharpe Inc. p. 256-278, 1981.

TRIVINOS, A. N. S. Introdução à pesquisa em ciências sociais: a pesquisa qualitativa em educação. São Paulo: Atlas, 2011.

Recebido em maio de 2019.

Aprovado em outubro de 2019. 